\title{
Performed Substance Administration Interruption Duration
}

National Cancer Institute

\section{Source}

National Cancer Institute. Performed Substance Administration Interruption Duration.

NCI Thesaurus. Code C95376.

The time span of a disruption in a performed substance administration. 